values should rarely exceed \pm 30 per cent. The numbers in Table 2 suggest a general tendency towards decreasing abundance the higher the trophic level.

A detailed description and discussion of these experiments will be presented elsewhere.

R. FUKAI*

W. W. MEINkE

Department of Chemistry,

University of Michigan,

Ann Arbor, Michigan. June 1 .

* Present address: Tokai Regional Fisheries Research Laboratory, Tsukishima, Chuo-ku, Tokyo, Japan.

${ }^{1}$ Fukai, R., and Meinke, W. W., Limnology and Oceanography, October, 1959 (in the press).

${ }^{2}$ Meinke, W. W., Nucleonics (July, 1959, in the press).

'Strominger, D., Hollander, J M., Seaborg, G. T., Rev. Mod. Phys., 30 , 585 (1958).

' Hughes, D. J., Harvey, J. A., U.S. Atomic Energy Commission Rept. BNL-325 (July, 1955).

\section{Preparation of Crystalline trans-trans Methyl Linoleate Hydroperoxide}

A метноD has been worked out for the continuous separation of the hydroperoxide of oxidizing methyl linoleate; the oxidation level of the latter being maintained at about 2 per cent. The product obtained has been purified and ultimately crystallized.

Methyl linoleate, prepared by debromination of tetrabromostearic acid, was oxidized in solution in petroleum ether (b.p. $60-80^{\circ}$ C.) with oxygen gas, the resulting peroxide being continuously extracted from solution by finely dispersed 85 per cent aqueous methanol saturated with petroleum ether. In this way, the peroxide value of the oxidizing methyl linoleate was kept within the range 55-70 $\langle\mathrm{ml} .0 .002 \mathrm{~N}$ sodium thiosulphate per gm.), and the tendency for the reaction to proceed beyond the hydroperoxide stage was reduced to a minimum.

The methanol solution obtained usually contained equal weights of hydroperoxide and unchanged ester, which were then separated by partition between 85 per cent aqueous methanol and petroleum ether (b.p. $60-80^{\circ}$ C.). The product finally obtained from the combined methanol fractions was a pale yellow oil with a peroxide value of 3,400 as determined iodometrically, which is known to give higher values than theoretical, and an $E$ ( 1 per cent, $1 \mathrm{~cm}$.) of 810 at $231.5 \mathrm{~m} \mu$ in ethanol $(\varepsilon=26,400)$.

An infra-red spectrum of the product showed a strong band at $2.92 \mu$ (the hydroperoxide group) ${ }^{1}$, a strong maximum at $10 \cdot 10 \mu$ and a weaker one at $10.52 \mu$, together with indications of the presence of a carbonyl group, in addition to the ester. The material thus appeared to be a mixture of cis and trans conjugated diene hydroperoxides contaminated with a small quantity of decomposition products.

The hydroperoxide was purified further by two crystallizations from petroleum ether (b.p. $40-60^{\circ}$ C.) at $-35^{\circ}$ and a further two from ethanol at $-76^{\circ}$ to yield a compound with an $E$ (1 per cent, $1 \mathrm{~cm}$.) of 890 at $231.5 \mathrm{~m} \mu(\varepsilon=29,000)$. Further crystallization from ethanol produced no change in the extinction coefficient at $231.5 \mathrm{~m} \mu$. The infra-red spectrum showed that carbonyl decomposition products had been removed by crystallization. In addition although there was strong absorption at $10 \cdot 11 \mu$ there was no band at $10.52 \mu$, which indicates that the product was pure conjugated trans-trans-methyl linoleate hydroperoxide.
Experiments verifying the predominance of the 9 and 13-hydroperoxides in the product ${ }^{2}$ are at present being concluded and will soon be published together with details of the experiments outlined in this communication.

The work described in this paper was carried out as part of the programme of the Department of Scientific and Industrial Research.

\section{A. BANKS}

S. FAzAKRrLey*

J. N. KEAY

J. G. M. Sмrтн*

Torry Research Station,

Department of Scientific and Industrial Research, Aberdeen.

June 22.

* Members of the staff of the Herring Industry Board. ${ }^{1}$ Lemon, H. W., Kirby, E. M., and Knapp, R. M. Can. J. Technol., 29,

Bergström, S., Arkiv för Kemi, Min-Geol., A21, 14 (1945).

\section{BIOCHEMISTRY}

\section{A Concave Concentration Gradient of Methanol in Chloroform Employed in Elution of Lipids from Silicic Acid}

In several laboratories, where whole lipid extracts are chromatographed on silicic acid in chloroformmethanol, experience has suggested the need for continuous concave gradient elution. Devices are described in the literature for producing concave gradients of solutes in aqueous solution, but they are unsuitable for chloroform-methanol mixtures: they fail for liquids of unequal density, waste eluent, or are not easily constructed without rubber joints, greased stopcocks, etc. Hitherto, therefore, discontinuous gradients or continuous linear or convex gradients have been used for elution of lipids.

Fig. 1 shows a simple and reliable apparatus, possessing none of the above disadvantages, which

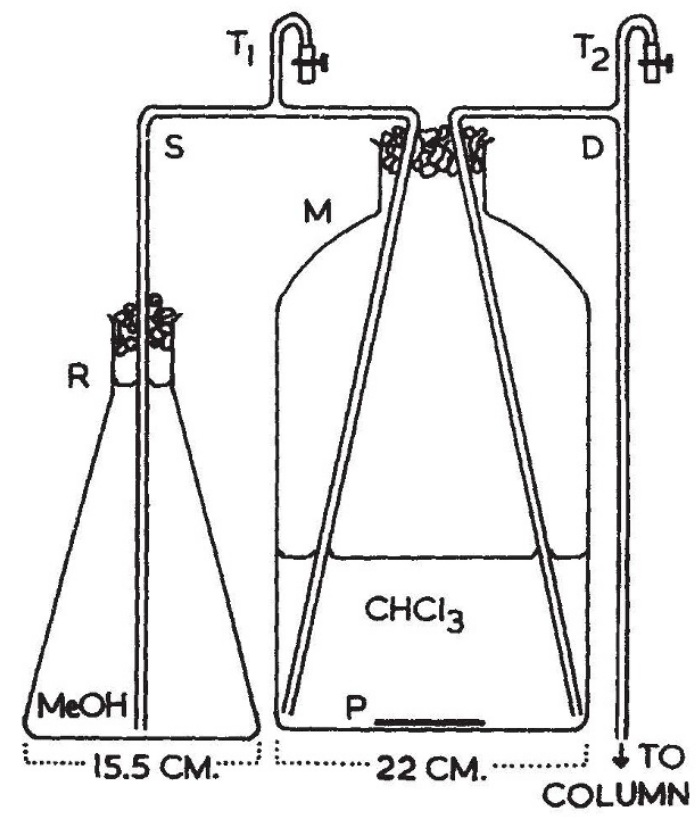
Fig. 1. Apparat us for producing a concave concentration gradient. 